\title{
SATUAN EKSPRESI PENAMAAN DAN PERSAMAAN WARNA DALAM PRODUK LIPSTIK
}

\section{EXPRESSION UNITS OF LIPSTICK PRODUCTS' COLOR LIKENESS AND LABELING}

\author{
Elen Inderasari dan Wahyu Oktavia \\ Institut Agama Islam Negeri Surakarta \\ Pos-el: oktaviawahyu17@gmail.com
}

*) Naskah masuk: 22 Maret 2019. Penyunting: Nurul Masfufah, M.Pd. Suntingan I: 15 April 2019. Suntingan II: 3 Mei 2019.

\begin{abstract}
Abstrak
Lipstik menjadi salah satu elemen perias yang digunakan untuk memberikan warna pada bibir dalam melengkapi penampilan kaum wanita. Tujuan penelitian ini untuk mendeskripsikan satuan ekspresi penamaan dan persamaan warna dalam produk lipstik. Penelitian ini berfokus pada aspek semantik. Metode yang digunakan dalam penelitian ini adalah metode deskriptif kualitatif yang hasilnya berupa pendeskripsian kata-kata. Teknik pengumpulan data menggunakan teknik dengan pengamatan dan pencatatan. Adapun teknik analisis data dilakukan dengan tiga tahapan yaitu, proses mencari data, mengelola data, dan menyajikan data. Hasil penelitian menunjukkan adanya (a) wujud satuan ekspresi warna pada produk lipstik, (b) satuan ekspresi penamaan warna lipstik, dan (c) satuan ekspresi persamaan warna lipstik.
\end{abstract}

Kata kunci : semantik, satuan ekspresi, penamaan, persamaan, warna lipstik

\begin{abstract}
Lipstick is one of makeup elements used to give color to the lips to beautify women's appearance. The purpose of this study is to describe expression units for the naming and similarity of colors in lipstick products. It focuses on semantic aspects. The method used in this study is a qualitative descriptive. Data collection techniques used is observation and notes taking. It applies the data analysis techniques in three stages, namely the process of finding, managing, and presenting the data. The results of the study show that there are (a) expression units of color in the lipstick products, (b) expression units of labeling the lipstick colors, and (c) expression units of the lipstick color likeness.
\end{abstract}

Keywords: semantics, expression units, labeling, likeness, lipstick colors

\section{PENDAHULUAN}

Menurunnya tingkat permintaan akibat dari turunnya daya beli konsumen merupakan hal menakutkan yang harus dihadapi oleh produsen. Begitu juga pada minat pembelian produk lipstik sekarang ini. Kondisi tersebut menyebabkan semakin tinggi dan ketatnya persaingan antarprodusen dalam merebut konsumen. Untuk dapat bertahan dan merebut konsumen 
yang ada, para pemasar berlomba-lomba melakukan suatu aktivitas-aktivitas pemasaran yang positif dan inovatif serta memiliki banyak strategi yang dapat digunakan untuk bertahan dan menang dalam persaingan (Michael, 2015:2).

Dalam era globalisasi seperti sekarang ini, situasi persaingan dalam pasar semakin tajam. Estetika dapat berfungsi sebagai perangkap emosional yang sangat ampuh untuk menarik perhatian konsumen (Ardiana, 2014:25). Salah satu usaha yang dapat ditempuh untuk menghadapi persaingan yang semakin tajam adalah melalui pemberian satuan ekspresi warna pada produk lipstik. Daya tarik suatu produk lipstik tersebut tidak dapat terlepas dari penamaan pada warna (Cenadi, 2015:4).

Pewarna bibir atau yang lebih dikenal dengan istilah lipstik merupakan salah satu kebutuhan masyarakat modern saat ini, khususnya bagi kaum perempuan. Sebagian masyarakat menggunakan lipstik untuk menambah kepercayaan diri mereka. Lipstik menjadi salah satu riasan wajah yang digunakan untuk memberikan warna pada bibir dalam melengkapi penampilan kaum wanita dimasa ini.

Budaya penggunaan pewarna bibir atau lipstik mulai menyebar ke masyarakat sehingga terjadi perubahan budaya penggunaan lipstik pada status sosial dan feminimitasnya. Pada masa ini lipstik digunakan dan dipakai oleh kaum perempuan saja. Selain itu, penggunaan lipstik tidak memandang gender. Pada masa ini lipstik telah mengalami keberagaman warna yang menandakan status sosial penggunanya.

Hal yang menarik dalam penelitian ini adalah terdapat keberagaman di dalam satuan ekspresi pengungkap warna pada lipstik, yaitu keberagaman asal bahasa dan satuan kebahasaan. Warna lipstik diklasifikasikan berdasarkan warna utama, serta penggunaan ranah semantik yang dapat membantu menjelaskan makna dari warna yang digunakan pada setiap nama lipstik.

Penelitian yang dilakukan Wahyu Oktavia (2018) dalam jurnal yang berjudul "Analisa Desain Visual dan Verbal Kemasan Parfum Eskulin terhadap Ketatnya Persaingan Globalisasi". Penelitian tersebut memiliki kesamaan pada objek datanya yaitu sama-sama mengenai tentang makna warna. Adapun perbedaannya terletak pada objek yang dikaji. Pada penelitian sebelumnya menggunakan objek kajian produk parfum dan pada penelitian yang akan dilakukan lebih menggunakan kajian produk lipstik. Hasil penelitian menunjukkan terdapat cara produsen dalam mengeksiskan produknya, antara lain membuat daya tarik pada kemasan. Dalam hal ini ada dua jenis pengklasifikasian desain kemasan, yaitu (1) desain visual yang berupa warna dan gambar, (2) desain verbal yang berupa hari dan aktivitas.

Berbeda dengan pendapat Dwi Kurniasih (2017) dalam jurnal yang berjudul "Satuan Ekspresi pada Kemasan Aqua" yang memiliki kesamaan pada subjek yang digunakan yaitu sama-sama mengenai satuan ekspresi, tetapi perbedaannya terletak pada pemilihan objek. Penelitian sebelumnya menggunakan objek aqua sedangkan penelitian yang akan dilakukan menggunakan objek lipstik. Hasil penelitian menunjukkan bahwa satuan ekspresi kebahasaan yang ada pada kemasan botol Aqua memiliki lima bentuk satuan kebahasaan, yakni akronim, kata, frasa, reduplikasi, dan singkatan.

Dari hasil penelitian yang relevan di atas, peneliti memiliki alasan yang kuat serta menarik untuk dilakukan penelitian lebih lanjut dari aspek semantiknya yang berkaitan dengan satuan ekspresi pada penamaan dan persamaan warna lipstik yang telah ditemukan dari brand produk lipstik. Produk lipstik yang dimaksud adalah make over, oriflame, Red-A, purbasari, wardah, 
sari ayu, LT Pro dan avione. Bentuk dan beragamnya nama yang terdapat dalam lipstik menjadi satuan ekspresi kebahasaan baru dikalangan anak muda yang mencerminkan tuturan yang ada di lingkungan. Keberagaman nama yang ada pada lipstik memiliki keunikan tersendiri yang ditujukan untuk menarik konsumen pada produk yang ditawarkan.

Penelitian ini dapat dikategorikan penelitian mutakhir dan original karena belum ada penelitian yang mengkaji satuan ekspresi pada ragam bahasa yang terdapat pada lipstik berdasarkan aspek semantik. Tujuan penelitian yang akan dicapai dalam Satuan Ekspresi Pada Lipstik Berdasarkan Nama Dan Warna adalah pertama, menjelaskan satuan ekspresi penamaan pada warna lipstik. Kedua, menjelaskan satuan ekspresi persamaan warna pada nama lipstik.

\section{TEORI}

\section{Warna}

Warna merupakan jenis komunikasi nonverbal yang memiliki suatu makna tertentu. Fakor estetik warna merupakan salah satu faktor penting dalam desain gambaran kehidupan. Setiap warna memiliki arti karakteristik tertentu. Yang dimaksud karakteristik di sini adalah ciri-ciri atau sifat khas yang dimiliki oleh suatu warna (Rastati, 2008). Dalam hal ini warna memiliki peranan yang sangat penting dalam kehidupan manusia. Adanya keterkaitan yang kuat dengan emosi, warna dapat mengakibatkan energi dan menimbulkan mood atau perasaan tertentu, bahkan mampu untuk mengungkapkan kepribadian diri seseorang. Warna memiliki kekuatan untuk menyembuhkan serta menyeimbangkan emosi, serta dapat menyeimbangkan keselarasan perasaan. Pemilihan warna oleh seseorang, menurut teori atribusi, dapat disebabkan oleh faktor personal dan faktor situasional. Faktor personal erat kaitannya dengan ketertarikan atau kesukaan terhadap suatu hal, sedangkan faktor situasional seringkali tindakan seseorang dipengaruhi oleh lingkungan seseorang (Hapsari, 2010).

Faktor estetik warna merupakan salah satu faktor penting di dalam kehidupan (Lituhayu, 2012). Faktor warna dapat menimbulkan kesan atau suasana hati seseorang bahkan pengaruh rangsangan tertentu yang dapat memberikan dampak yang baik dalam kondisi emosional seseorang. Kesan ini kemudian diterjemahnkan sebagai sebuah efek psikologis yang mempengaruhi perasaan bahkan kejiwaan manusia. Penggunaan warna didalam proses komunikasi dapat dikategorikan sebagai pesan untuk menentukan karakter (Hapsari, 2010). Arti warna dalam ilmu komunikasi yaitu suatu proses penyampaian pikiran atau perasaan seseorang dengan menggunakan lambang (simbol) sebagai media. Lambang di dalam proses komunikasi yaitu meliputi bahasa, isyarat, gambar, warna dan lain sebagainya. Yang secara langsung mampu menerjemahkan pikiran atau perasaan seseorang (Oktavia, 2018).

Pemilihan warna tidak hanya sekadar mengikuti selera pribadi berdasarkan perasaan saja, tetapi telah memilih dengan penuh kesadaran akan kegunaannya terhadap cara otak menerima serta menginterpretasikan warna. Kemudian perkembangan bidang psikologi juga membawa warna menjadi objek perhatian bagi para ahli psikologi (Rosyidah, 2010). Warna dapat pula menggambarkan suasana hati seseorang. Selain itu telah banyak dibuktikan melalui percobaan-percobaan bahwa warna mempengaruhi kegiatan fisik dan mental (Lituhayu, 2012).

Banyaknya nama-nama warna pada lipstik menunjukkan makna yang berbeda serta memiliki fungsi atau tujuan tertentu 
yang akan disampaikan pada konsumen. Pada kenyataannya dewasa ini, nama-nama warna yang digunakan dalam penamaan lipstik terjadi pergeseran atau perubahan makna dari makna gramatikal berubah menjadi makna leksikal. Di mana ditandai dengan munculnya nama-nama lipstik seperti guava jam, hello ruby dan sebagainya yang memiliki makna berbeda dari makna secara konteks kata atau kalimat.

Warna lipstik dibedakan dengan cara pemberian nomor yang menjadi pembeda antara warna yang satu dengan yang lain. Selain pemberian nomor nama warna juga diikutsertakan dalam penamaan lipstik yang berdasarkan jenis warna. Dengan demikian, warna lipstik dibedakan dengan memberikan nama yang menjadikan ciri khas lipstik. Banyaknya warna lipstik yang diciptakan, tentunya memiliki perbedaan antara satu dengan yang lainnya. Terdapat kode atau nama yang digunakan untuk memberikan identitas pada setiap warna lipstik, kode atau nama yang digunakan tentu berbeda serta memiliki keunikan antara brand lipstik satu dengan brand yang lainnya. Kode atau nama yang digunakan pada lipstik memiliki perbedaan serta keunikan tersendiri,

Dewasa ini, lipstik memiliki beragam warna, jenis dan merk yang beredar di kalangan masyarakat. Oleh sebab itu, untuk membedakan warna dan jenis lipstik antara brand satu dengan brand yang lainnya dibutuhkan satuan ekspresi penamaan untuk mengungkap warna lipstik yang sesuai dengan brand warna lipstik yang ada. Misalnya, warna merah, pink, nude, orange, coklat, dan ungu yang merupakan satuan ekspresi penamaan warna pada lipstik. Sementara itu untuk menarik perhatian para pembeli, dewasa ini, warna-warna tersebut lebih beragam dalam pegungkapan warna yang digunakan untuk memberikan kode pada setiap lipstik. Misalnya, pengungkapan warna dengan menggunakan nama, seperti red dicted, fuschionately, see you latte, pink me, feeling red, pinkcredible, mauve on, oh so nude, hello ruby dan masih banyak lagi. Hal tersebut bukan hanya sekadar membedakan jenis warna, melainkan terdapat juga konsep tertentu yang ingin disampaikan pembuat warna lipstik melalui satuan ekspresi pengungkap warna pada lipstik tersebut.

\section{Semantik}

Semantik berasal dari bahasa yunani dari kata sema yang berarti tanda atau lambang. Dalam bahasa Yunani, ada beberapa kata yang menjadi dasar kata, yaitu semantikos (memaknai), semainein (mengartikan), dan sema (tanda). Sema juga berarti kuburan yang mempunyai tanda yang menerangkan siapa yang di kubur. Semantik dapat dipahami sebagai tanda yang menerangkan tentang asal kata yang disebutkan pertama kali. Secara terminologis semantik merupakan bagin dari struktur bahasa yang berhubungan dengan makna ungkapan atau sistem penyelidikan makna dari suatu bahasa. Semantik merupakan pendekatan linguistik yang tidak akan terlepas dari unsur kebahasaan (Leech, 2003:12).

Semantik merupakan bagian linguistik yang menjadi bagian makna dari bahasa. Semantik menelaah lambang-lambang atau tanda-tanda yang menyatakan makna, hubungan makna yang satu dengan makna yang lain dan pengaruhya terhadap manusia dan masyarakat. Oleh sebab itu, semantik mencakup makna-makna kata, perkembangan dan perubahannya. Dengan lebih rinci semantik adalah cabang linguistik yang bertugas menelaah makna kata, bagaimana mulanya, bagaimana perkembangannya, dan apa sebabnya terjadi perubahan makna dalam sejarah bahasa (Suwandi, 2011: 2). Sebagai studi tentang makna, semantik merupakan pusat studi tentang pikiran manusia berupa proses berpikir, kognisi, konseptualisasi yang berkaitan dengan cara mengklasifikasikan dan mengemukakan peng- 
alaman tentang dunia nyata melalui bahasa (Leech, 2003).

Persoalan makna merupakan hal yang menarik untuk dikaji dalam kehidupan sehari-hari. Dengan makna orang bisa memahami, mengartikan dan menafsirkan apa yang telah dilihat, dibaca dan dirasa. Makna merupakan istilah yang ambigu dan paling kontroversial dalam teori tentang bahasa (Ullmann, 2007: 65). Makna dapat dibedakan berdasarkan beberapa kriteria antara lain berdasarkan jenis semantiknya, nilai rasa, referensi, dan ketepatan makna (Suwandi, 2011: 79).

Makna dapat pula ditinjau dari pendekatan analitik atau referensial, yakni pendekatan yang mencari esensi makna dengan cara menguraikannya. Pendekatan tersebut berbeda dengan pendekatan operasional yang mempelajari kata dalam penggunaannya dan menekankan pada sisi operasionalnya yang dipertimbangkan dari fungsi yang dapat dibedakan atas sense (pengertian), feeling (perasaan), tone (nada), intension (tujuan) (Djajasudarma, 2008:3).

Penamaan dikatakan dalam bahasa yang berarti sistem tanda yang digunakan untuk berkomunikasi. Tanda yang dimaksudkan adalah berupa lambang. Lambang dalam bahasa berisi dua yaitu bentuk dan makna. Nama juga dibedakan dari definisi dan istilah yang berisi suatu pembatasan tentang suatu fakta, peristiwa, benda dan proses (Pateda, 2001: 62). Lebih luas menurut Aristoteles (dalam Pateda, 2001: 63) pemberian nama adalah soal perjanjian, konvensi. Yang dimaksud soal perjanjian disini bukan berarti bahwa dahulu ada sidang masalah nama untuk sesuatu yang diberi nama. Salah satunya yatu penamaan pada produk lipstik, nama-nama tersebut biasanya berasal dari seseorang penulis, pengarang, tokoh masyarakat yang kemudian dipopulerkan oleh masyarakat, baik melalui media massa elektronik maupun nonelektronik.

Persamaan memiliki makna secara harfiah, yaitu nama lain untuk benda yang sama. Untuk mendefinisikan persamaan ada tiga batasan yang dapat dikemukan. Batasan atau definisi itu ialah kata-kata dengan acuan ekstra linguistik yang sama, kata-kata yang mengandung makna yang sama, dan kata-kata yang dapat disubstitusi dalam konteks yang sama (Pateda, 2001: 223). Berbeda dengan Verhaar (1983: 132) yang mengatakan bahwa persamaan adalah ungkapan yang kurang lebih sama maknanya dengan ungkapan lain. Artinya, meskipun maknanya sama, tetapi juga sedikit memperlihatkan perbedaan-perbedaannya. Lebih lanjut, Lyons dalam Pateda (2001: 224) membedakan persamaan dalam dua kata, yaitu persamaan yang sempurna dan persamaan yang absolut. Suatu persamaan kata dikatakan sempurna apabila kata-kata tersebut mengandung makna deskriptif, ekspresif, dan sosial yang sama. Sementara itu, persamaan kata absolute, yaitu apabila katakata tersebut mempunyai distribusi yang sama dan bermakna secara sempurna di dalam kehadirannya pada semua konteks.

\section{METODE}

Jenis penelitian yang digunakan dalam penelitian ini adalah deskriptif kualitatif yang digunakan untuk menggambarkan data serta menginterpretasikan objek sesuai dengan keadaan yang sebenarnya (Mahsun, 2006:17). Metode yang digunakan dalam penelitian ini adalah metode observasi langsung dalam mengumpulkan data. Teknik penelitian yang digunakan, yaitu dengan mengamati, dan mencatat secara langsung ragam satuan ekspresi warna yang ada pada brand lipstik make over, oriflame, Red-A, purbasari, wardah, sari ayu, LT Pro dan avione. Keseluruhan data diambil dari brosur dan website produk lipstik. Jumlah data 
warna lipstik yang ditemukan penulis adalah 50 data yang diklasifikasikan berdasarkan penamaan dan persamaan warna.

Ada tiga teknik analisis data dalam melaksanakan penelitian ini yaitu, proses mencari data, mengelola data, dan menyajikan data (Sugiyono, 2014:35). Pada proses pencarian data, peneliti menggunakan beberapa cara yaitu, mengamati dan mencatat. Mencari data dengan mengamati data-data yang akan diteliti dapat membuat peneliti memiliki konsep terhadap kajian yang akan digunakan. Teknik catat adalah teknik menjaring data dengan mencatat hasil pencarian data. Kegiatan mencatat dilakukan sebagai lanjutan dari kegiatan mencari data dari sumber tertulis. Data yang telah dicatat kemudian diklasifikasikan berdasarkan kebutuhan penelitian. Setelah dilakukan analisis data, kemudian disusun dalam bentuk laporan.

\section{HASIL DAN PEMBAHASAN}

Wujud Satuan Ekspresi Warna Pada Produk Lipstik

Wujud satuan ekspresi warna pada produk lipstik dapat dilihat dari beberapa produk-produk temuan data lipstik yang sudah ditemukan, antara lain sebagai berikut:

Tabel 1

\begin{tabular}{|l|l|l|}
\hline Produk & Nama Pada Lipstik & Arti \\
\hline Make over & Lavish & Mewah \\
\cline { 2 - 3 } & Vanity & Kesombongan \\
\cline { 2 - 3 } & Secret & Rahasia \\
\cline { 2 - 3 } & Coquette & Genit \\
\cline { 2 - 3 } & Savvy & Pengertian \\
\cline { 2 - 3 } & Posh & Mewah \\
\cline { 2 - 3 } & Dainty & Halus \\
\cline { 2 - 3 } & Classic & Sederhana \\
\hline Oriflame & Toffe dream & Mimpi yang bagus \\
\cline { 2 - 3 } & Satin rose & Lembut \\
\cline { 2 - 3 } & Coral dream & Mimpi yang menantang \\
\cline { 2 - 3 } & Plush peach & Berat \\
\cline { 2 - 3 } & Red velvet & Buruk \\
\hline Red-A & Strawberry jam & Selai stroberry \\
\cline { 2 - 3 } & Lychee jam & Selai leci \\
\cline { 2 - 3 } & Cherry jam & Selai cherry \\
\cline { 2 - 3 } & Guava jam & Selai jambu biji \\
\cline { 2 - 3 } & Grape jam & Selai anggur \\
\cline { 2 - 3 } & Frozen heart & Hati yang membeku \\
\cline { 2 - 3 } & I'm in love & Saya sedang jatuh cinta \\
\hline
\end{tabular}

\begin{tabular}{|c|c|c|}
\hline \multirow[t]{5}{*}{ Purbasari } & Vinca & Vinca \\
\hline & Azalea & Azalea \\
\hline & Lantana & Lantana \\
\hline & Zinnia & Zinnia \\
\hline & Fressia & Fressia \\
\hline \multirow[t]{7}{*}{ Wardah } & My honey bee & Kekasihku \\
\hline & Heart beet & Jantung hati \\
\hline & See you late & Selamat bertemu \\
\hline & Pink me & Kesayanganku \\
\hline & Mauve on & Hapuslah \\
\hline & Berry pretty & Sungguh cantik \\
\hline & Saturday night & Malam minggu \\
\hline \multirow[t]{5}{*}{ Sari Ayu } & Satin finish & Lembut \\
\hline & Metallic & Segar \\
\hline & Coral & Cerah \\
\hline & Flamboyan & Elegan \\
\hline & Rosewood & Manis \\
\hline \multirow{7}{*}{ LT Pro } & Cooltone & Dingin \\
\hline & Barbie & Manis \\
\hline & Nude beight & Pucat \\
\hline & Warm tone & Terang \\
\hline & Touch & Seksi \\
\hline & Mauvy & Kalem \\
\hline & Metalic & Segar \\
\hline \multirow[t]{5}{*}{ Avione } & True love & Benar-benar cinta \\
\hline & Valentine & Kasih sayang \\
\hline & Merry me & Menikah denganku \\
\hline & Quinn & Seorang ratu \\
\hline & Chesnut & Melembutkan \\
\hline
\end{tabular}

\section{Satuan Ekspresi Penamaan Produk Lipstik}

Satuan ekspresi penamaan pada produk lipstik dapat dilihat dari beberapa nama yang diberikan oleh brand setiap produk lipstik. Penamaan pada produk lipstick, antara lain sebagai berikut.

\section{Tabel 2}

\begin{tabular}{|l|l|l|}
\hline Produk & Nama Pada Lipstik & Arti \\
\hline Make Over & Lavish & Mewah \\
\cline { 2 - 3 } & Vanity & Kesombongan \\
\cline { 2 - 3 } & Secret & Rahasia \\
\cline { 2 - 3 } & Coquette & Genit \\
\cline { 2 - 3 } & Savvy & Pengertian \\
\cline { 2 - 3 } & Posh & Mewah \\
\cline { 2 - 3 } & Dainty & Halus \\
\cline { 2 - 3 } & Classic & Sederhana \\
\hline
\end{tabular}

Pada temuan data di atas, dapat diketahui bahwa dalam penamaan produk lipstik Make Over lebih cenderung menggunakan kata-kata yang ada pada karakteristik sifat-sifat yang dimiliki oleh manusia seperti sifat mewah, sombong, sederhana, rahasia, genit, serta halus. 
Tabel 3

\begin{tabular}{|l|l|l|}
\hline Produk & Nama Pada Lipstik & Arti \\
\hline Oriflame & Toffe dream & Mimpi yang bagus \\
\cline { 2 - 3 } & Satin rose & Lembut \\
\cline { 2 - 3 } & Coral dream & Mimpi yang menantang \\
\cline { 2 - 3 } & Plush peach & Berat \\
\cline { 2 - 3 } & Red velvet & Buruk \\
\hline
\end{tabular}

Dari temuan data di atas, dilihat bahwa penggunaan penamaan produk lipstik Oriflame lebih mengutamakan penamaan pada lipsik dengan istilah ekspresi bermimpi seseorang, seperti pada mimpi yang bagus, lembut, menantang, berat maupun buruk.

Tabel 4

\begin{tabular}{|l|l|l|}
\hline Produk & Nama Pada Lipstik & Arti \\
\hline Red-A & Strawberry jam & Selai stroberry \\
\cline { 2 - 3 } & Lychee jam & Selai leci \\
\cline { 2 - 3 } & Cherry jam & Selai cherry \\
\cline { 2 - 3 } & Guava jam & Selai jambu biji \\
\cline { 2 - 3 } & Grape jam & Selai anggur \\
\cline { 2 - 3 } & Frozen heart & Hati yang membeku \\
\cline { 2 - 3 } & I'm in love & Saya sedang jatuh cinta \\
\hline
\end{tabular}

Pada data di atas, produk lipstik RedA dalam penamaannya diklasifikasikan menjadi dua penamaan yaitu menggunakan ekspresi dengan kata-kata yang natural yang diaplikasikan dengan nama-nama buah seperti selai stroberry, leci, cherry, jambu biji dan anggur. Selain itu dalam penamaan warna pada produk Red-A juga menggunakan ekspresi ungkapan perasaan cinta seperti saya sedang jatuh cinta dan hati yang sedang membeku.

Tabel 5

\begin{tabular}{|l|l|l|}
\hline Produk & Nama Pada Lipstik & Arti \\
\hline Purbasari & Azalea & Azalea \\
\cline { 2 - 3 } & Lantana & Lantana \\
\cline { 2 - 3 } & Zinnia & Zinnia \\
\cline { 2 - 3 } & Freesia & Freesia \\
\hline
\end{tabular}

Dari data di atas, penamaan pada produk lipstik Purbasari lebih cenderung menggunakan sebutan kata dari nama-nama seseorang. Seperti pada sebutan nama aza dari azalea, ana dari lantana, nia dari zinnia, dan resi dari fressi.
Tabel 6

\begin{tabular}{|l|l|l|}
\hline Produk & Nama Pada Lipstik & Arti \\
\hline Wardah & My honey bee & Kekasihku \\
\cline { 2 - 3 } & Heart beet & Jantung hati \\
\cline { 2 - 3 } & See you late & Selamat bertemu \\
\cline { 2 - 3 } & Pink me & Kesayanganku \\
\cline { 2 - 3 } & Mauve on & Hapuslah \\
\cline { 2 - 3 } & Berry pretty & Sungguh cantik \\
\cline { 2 - 3 } & Saturday night & Malam minggu \\
\hline
\end{tabular}

Dari data di atas, produk lipstik Wardah lebih banyak menggunakan ekspresi penamaan dengan ungkapan perasaan kecintaan dan kegembiraan seperti pada kata kekasihku, jantung hatiku, kesayanganku dan sungguh cantik.

Tabel 7

\begin{tabular}{|l|l|l|}
\hline Produk & Nama Pada Lipstik & Arti \\
\hline Sari Ayu & Satin finish & Lembut \\
\cline { 2 - 3 } & Metallic & Tampil beda \\
\cline { 2 - 3 } & Coral & Cerah \\
\cline { 2 - 3 } & Flamboyan & Elegan \\
\cline { 2 - 3 } & Rosewood & Manis \\
\hline
\end{tabular}

Dari data di atas, penamaan dalam produk lipstik Sari Ayu lebih cenderung menggunakan ungkapan kesayangan yang hampir setiap saat selalu diucapkan oleh lakilaki kepada perempuan seperti lembut, natural, tampil beda, cerah, elegan dan manis.

Tabel 8

\begin{tabular}{|l|l|l|}
\hline Produk & Nama Pada Lipstik & Arti \\
\hline LT Pro & Cooltone & Dingin \\
\cline { 2 - 3 } & Barbie & Manis \\
\cline { 2 - 3 } & Nude beight & Pucat \\
\cline { 2 - 3 } & Warm tone & Terang \\
\cline { 2 - 3 } & Touch & Seksi \\
\cline { 2 - 3 } & Mauvy & Kalem \\
\cline { 2 - 3 } & Metalic & Segar \\
\hline
\end{tabular}

Dari data di atas, satuan ekspresi penamaan dalam produk lipstik LT Pro lebih banyak menggunakan kata-kata keterangan sifat seperti kata dingin, manis, pucat, terang, seksi, kalem dan segar. Di mana kata-kata ini sering digunakan dan selalu terdengar disekitar kita. 
Tabel 9

\begin{tabular}{|l|l|l|}
\hline Produk & Nama Pada Lipstik & Arti \\
\hline Avione & True love & Benar-benar cinta \\
\cline { 2 - 3 } & Valentine & Kasih sayang \\
\cline { 2 - 3 } & Merry me & Menikah denganku \\
\cline { 2 - 3 } & Quinn & Seorang ratu \\
\cline { 2 - 3 } & Chesnut & Melembutkan \\
\hline
\end{tabular}

Dari data di atas, dalam satuaan penamaan produk lipstik Avione cenderung menggunakan kata-kata yang romantis seperti kata true love, valentine, chesnut. Penggunaaan kata-kata romantis tersebut diharapkan dapat menarik dari sisi persuasif seorang wanita.

\section{Satuan Ekspresi Persamaan Warna}

\section{Tabel 10}

\begin{tabular}{|l|l|l|}
\hline Warna & Persamaan warna & Arti \\
\hline Merah & Merah crimson & Merah crimson \\
\cline { 2 - 3 } & Merah candy & Merah permen \\
\cline { 2 - 3 } & Merah cherry & Merah buah cerry \\
\cline { 2 - 3 } & Merah garnet & Merah tua \\
\cline { 2 - 3 } & Bright red & Merah terang \\
\cline { 2 - 3 } & Dark red & Merah gelap \\
\cline { 2 - 3 } & Dark red hint brown & Merah gelap kecoklatan \\
\cline { 2 - 3 } & Medium red & Merah sedang \\
\cline { 2 - 3 } & Dark blood red & Merah darah gelap \\
\hline
\end{tabular}

Merah menjadi warna palet lipstik dasar yang dimiliki hampir semua wanita. Apalagi lipstik merah juga cocok dikenakan di berbagai waktu. Sering kali orang yang menggunakan lipstik merah diidentikkan dengan orang yang memiliki keperibadian yang percaya diri, penuh keyakinan dan tegas. Namun penggunaan lipstik warna merah juga didefinisikan sebagai orang yang nakal dan tidak takut menjadi pusat atensi. Selain itu juga warna merah memiliki gaya busana yang unik dan stylish.

\section{Tabel 11}

\begin{tabular}{|l|l|l|}
\hline Warna & Persamaan warna & Arti \\
\hline $\begin{array}{l}\text { Pink atau } \\
\text { Merah }\end{array}$ & Bright pink & Merah muda cerah \\
\cline { 2 - 3 } & Pink bublegum & Merah muda permen karet \\
\cline { 2 - 3 } & $\begin{array}{l}\text { Pink peach with } \\
\text { brown }\end{array}$ & Merah muda kecoklatan \\
\cline { 2 - 3 } & Red pink & Merah muda \\
\cline { 2 - 3 } & Soft pink & Merah muda lembut \\
\cline { 2 - 3 } & Nude pinkish & Merah muda pucat \\
\cline { 2 - 3 } & Dusty medium pink & $\begin{array}{l}\text { Merah muda sedang } \\
\text { berdebu }\end{array}$ \\
\cline { 2 - 3 } & Bluish medium pink & $\begin{array}{l}\text { Merah muda menengah } \\
\text { kebiruan }\end{array}$ \\
\cline { 2 - 3 } & Pink mauve & Merah muda keunguan \\
\hline
\end{tabular}

Selain merah, lipstik warna pink juga banyak sekali di koleksi oleh wanita. Salah satu yang diberikan oleh warna pink yaitu sifat yang cenderung empatis dan ambisius dalam waktu yang bersamaan. Orang yang memakai warna lipstik pink dipandang sebagai orang yang suka bermain, suka mengambil keputusan yang besar, serta tidak suka menghambur-hamburkan uang untuk fashion yang terlalu mahal.

Tabel 12

\begin{tabular}{|l|l|l|}
\hline Warna & Persamaan warna & Arti \\
\hline Orange & Orange merah bata & Orange merah bata \\
\cline { 2 - 3 } & Orange tiger & Orange harimau \\
\cline { 2 - 3 } & Orange pink & Orange merah muda \\
\hline
\end{tabular}

Wanita yang suka menghias bibirnya dengan warna orange diibaratkan seperti gelas kaca yang setengah penuh. Mereka siap untuk mengisis gelas tersebut dengan sisi unik dan klasik sekaligus. Orang yang sering memakai lipstik warna oranye atau coral juga dikatakan sebagai eksperimental. Sayangnya hal tersebut kadang membuat mereka suka melanggar batas dan suka berubah-ubah.

Tabel 13

\begin{tabular}{|l|l|l|}
\hline Warna & Persamaan warna & Arti \\
\hline Cokelat & Peachy brown & Cokelat peachy \\
\cline { 2 - 3 } & Deep brownish magenta & Cokelat magenta \\
\cline { 2 - 3 } & Warm brown & Cokelat hangat \\
\cline { 2 - 3 } & Nude brown & Cokelat pucat \\
\cline { 2 - 3 } & Pale organish brown & Cokelat putih pucat \\
\cline { 2 - 3 } & Medium brow & Cokelat sedang \\
\cline { 2 - 3 } & Coral brown & Cokelat karang \\
\cline { 2 - 3 } & Nude coklat-ungu & Cokelat ke unguan \\
\hline
\end{tabular}

Pemakaian lipstik warna cokelat serta taupe memang kurang di pilih oleh kaum wanita. Namun dua warna tersebut kembali digemari setelah sering dikenakan oleh Kylie Jenner. Orang yang suka memakai lipstik warna cokelat sering diperkirakan sebagai seorang yang mandiri dan bisa untuk diandalkan. Selain itu juga memiliki sisi romantis dan suka bernonstalgia dengan masa lalu. Wanita dengan bibir kecokelatan juga dikenal berdaya dan tidak takut dalam menggunakan kekuatan yang dimilikinya. 
Tabel 14

\begin{tabular}{|l|l|l|}
\hline Warna & Persamaan warna & Arti \\
\hline \multirow{4}{*}{ Nude } & Nature & Warna bibir \\
\cline { 2 - 3 } & Nude statue & Warna pucat patung \\
\cline { 2 - 3 } & Nude sculpture & Warna pucat arca \\
\hline
\end{tabular}

Sebagian wanita lebih suka menggunakan lipstik warna nude atau pucat daripada terang. Orang mungkin berpikir jika wanita itu tidak ingin terlihat menonjol dan pemalu. Tetapi hal tersebut belum tentu benar adanya. Pemakaian warna nude yaitu menandakan bahawa seorang wanita memiliki sifat yang damai, tenang serta mudan dalam berteman. Selain itu banyak orang yang selalu meminta pendapat pada wanita yang suka memakai warna nude.

\section{PENUTUP}

Bentuk dan beragamnya nama yang terdapat dalam lipstik menjadi satuan ekspresi kebahasaan baru dikalangan anak muda yang mencerminkan tuturan yang ada dilingkungan. Keberagaman nama yang ada pada lipstik memiliki keunikan tersendiri yang ditujukan untuk menarik konsumen pada produk yang ditawarkan. Penelitian ini terfokus pada aspek semantik yang berkaitan dengan satuan ekspresi pada penamaan dan persamaan warna lipstik yang telah ditemukan dari brand produk lipstik make over, oriflame, Red-A, purbasari, wardah, sari ayu, LT Pro dan avione. Hasil penelitian menunjukkan bahwa dari 50 data yang ditemukan kemudian data diklasifikasikan berdasarkan (a) wujud satuan ekspresi warna pada produk lipstik, (b) satuan ekspresi penamaan pada produk warna lipstik dan (c) satuan ekspresi persamaan warna yang dilihat dari warna merah, merah muda atau pink, cokelat, orange dan nude.

\section{DAFTAR PUSTAKA}

Ardiana, Erlita. 2014. Analisis Perbedaan Permintaan Pembelian pada Anak Berdasarkan Terpaan pesan Fantasi
Iklan Televisi dan Persepsi Realitas. Skripsi. Jurusan Ilmu Komunikasi. Universitas Diponegoro Semarang.

Cenadi, C. S. 2015. Peranan Desain dalam Dunia Pemasaran, 2(1),1--12.

Djajasudarma, Fatimah. 2008. Semantik 2:

Pemahaman Ilmu Makna. Bandung:

Refika Aditama.

Hapsari, S. U. H. 2010. Aplikasi Semiotik dan

Efek Psikologi Tampilan Warna Pada

Rumah Minimalis. Jurnal Riptek, 4 (1), 1-8 .

Kurniasih, Dwi. 2017. Satuan Ekspresi Pada

Kemasan Botol Aqua. Jurnal Bahasa

Lingua Scientia, 9 (2), 319-346.

Leech, G. 2003. Semantik. Yogyakarta: Pustaka Pelajar.

Lituhayu, C. 2012. Pengaruh Warna Terhadap Psikologi Pengguna dalam Perancangan Fasilitas Bedah Plastik Estetik, 1--7.

Mahsun. 2006. Metode Penelitian Bahasa. Jakarta: PT RajaGrafindo Persada.

Michael. A. 2015. Analisa Strategi Reposisi Merek dalam Persaingan Pasar, 1--7.

Oktavia, Wahyu. 2018. Analisa Desain Visual dan Verbal Kemasan Parfum Eskulin terhadap Ketatnya Persaingan Globalisasi. Jurnal Linguistik, 1 (2), 82--95. Pateda, Mansoer. 2001. Semantik Leksikal. Jakarta: Rineka Cipta.

Rastati, R. 2010. Konsep Warna dalam Kebudayaan. Universitas Indonesia.

Rosyidah, U. 2010. Model Penaksiran

Respon Emosi Berdasarkan Warna Menggunakan Metode Simple Additive Weighting. Jurnal Techno. 9 (1), 1--14.

Sugiyono. 2014. Metode Penelitian Kuantitatif Kualitatifdan RED. Bandung: Alfabeta. 
Suwandi, Sarwiji. 2011. Semantik Pengantar Kajian Makna. Yogyakarta: Media Perkasa.

Ullmann, Stephen. 2007. Pengantar Semantik. Yogyakarta: Pustaka Pelajar. 